\title{
PELATIHAN PEMBUATAN MEDIA PEMBELAJARAN MATEMATIKA BANGUN DATAR BAGI GURU-GURU SD BERTINGKAT NAIKOTEN
}

\author{
Christine K. Ekowati $^{1)}$, Ofirenty Elyada Nubatonis ${ }^{2)}$, Magdalena Wangge ${ }^{3)}$ \\ Program Studi Pendidikan Matematika FKIP Universitas Nusa Cendana, Indonesia ${ }^{1,2), 3)}$ \\ Pos-el : ekowatichristine@gmail.com ${ }^{1)}$; ofirenty@ staf.undana.ac.id ${ }^{2)}$; \\ magdalena.wangge@staf.undana.ac.id ${ }^{3)}$
}

Dikirim: 19, 08, 2020

Direvisi: 22, 08, 2020

Diterbitkan: 31, 08, 2020

\begin{abstract}
Abstrak
Kegiatan pengabdian ini bertujuan meningkatkan kemampuan guru-guru SD Bertingkat Naikoten membuat dan menggunakan media pembelajaran matematika bangun datar untuk mengatasi keterbatasan jumlah dan penggunaan media di kelas. Metode yang digunakan dalam mengatasi masalah yang dihadapi mitra adalah seminar, workshop, pendampingan, diskusi dan tanya jawab. Target khusus yang ingin dicapai dalam kegiatan pengabdian ini yaitu menghasilkan 13 paket media bangun datar untuk siswa sekolah dasar, menghasilkan modul petunjuk pembuatan media pembelajaran matematika dan modul petunjuk penggunaan media pembelajaran matematika.
\end{abstract}

Kata kunci : media, matematika, pembelajaran, bangun datar

\begin{abstract}
This program aims to improve the ability of elementary school teachers at SD Negeri Bertingkat Naikoten to create and use the flat-shape media and overcoming the limited quantity and used of mathematics learning media in the classroom. The methods used in overcoming problems that faced by partners are seminars, workshops, mentoring, discussions and question-answer method. The special target to be achieved in this program is to produce 13 flat-shapes media packages for elementary school students, produce an instruction for making mathematics learning media and an instruction for use of mathematics learning media.
\end{abstract}

Keywords : media, mathematics, learning, flat-shape

\section{PENDAHULUAN}

Mitra dalam program pengabdian ini adalah SD Bertingkat Naikoten. SD Bertingkat Naikoten I beralamat di Jalan Soeharto No 52 Keluarahan Naikoten I Kecamatan Maulafa Kota Kupang. SD Bertingkat Naikoten I memiliki guru kelas sebanyak 27 orang, 2 orang guru agama dan 3 guru olahraga. Masing-masing guru memiliki tugasnya masing-masing sesuai dengan profesi dan keahliannya. Guru-guru pada Sekolah mitra ini bertugas sebagai wali kelas dan mengasuh semua mata pelajaran kecuali mata pelajaran agama dan olahraga.

Dalam menjalankan tugasnya sebagai guru kelas, mata pelajaran matematika menjadi salah satu mata pelajaran yang wajib diajarkan kepada siswa-siswanya. Dalam mengajarkan matematika dengan model tematik, guru dituntut menyiapkan berbagai media pembelajaran untuk menanamkan konsep-konsep matematika bagi siswa.

Menurut Yayuk (2019) matematika adalah suatu ilmu yang mempelajari tentang perhitungan, pengkajian dan penggunaan nalar, kemampuan berpikir logis, kritis analitis dan sistematis. Oleh karena itu, dalam merancang pembelajaran, guru harus mampu 
mengidentifikasi karakteristik peserta didik dan kekhasan sehingga tujuan pembelajaran kognitif, afektif dan psikomotor dapat tercapai seutuhnya. Dalam mencapai tujuan ini, berbagai upaya perlukan dilakukan seperti penggunaan model, pendekatan dan metode yang sesuai dengan karakteristik peserta didik termasuk penggunaan media pembelajaran harus dipertimbangkan secara matang.

Menurut Mashuri (2019), sebagaimana kajian matematika adalah objek-objek yang bersifat abstrak berpotensi memunculkan berbagai kesulitan siswa dalam mempelajarinya, terutama bagi siswa kelas rendah. Fakta demikian, mendorong perlu media pembelajaran yang dapat memberi pengalaman visual bagi siswa dalam berinteraksi dengan objek-objek yang bersifat abstrak. Oleh karena itu, guru perlu memvisualisasikan konsep yang abstrak tersebut menjadi sesuatu yang nyata bagi siswa agar mudah dipahami.

Salah satu visualisasi konsep-konsep matematika adalah media pembelajaran. Menurut Riyana (2019), paradigma media pembelajaran matematika adalah sebagai alat visual/audio, sesuatu yang dipandang sebagai sesuatu yang dikembangkan secara sistemik serta berpegang teguh pada kaidah komunikasi, sesuatu yang merupakan bagian internal dalam pembelajaran matematika, serta dipandang sebagai sesuatu yang sengaja dikembangkan untuk atau dimanfaatkan untuk keperluan mengajar.

SD Negeri Bertingkat Naikoten memiliki beberapa peragaan/media pembelajaran untuk pelajaran IPA, IPS dan Matematika. Daftar jenis dan jumlah media pembelajaran ini dapat dilihat pada tabel berikut.

Tabel 1. Daftar Jenis Alat Bantu dan Media Pembelajaran IPA, IPS dan Matematika di SD Bertingkat Naikoten I

\begin{tabular}{|l|l|c|l|c|}
\hline No & \multicolumn{1}{|c|}{ Nama media } & Jumlah & Kondisi & Sumber perolehan \\
\hline 1. & $\begin{array}{l}\text { Poster Rangka Manusia ukuran } \\
(1 \times 1,5) \text { meter }\end{array}$ & 2 & Baik & Swadaya Sekolah \\
\hline 2. & $\begin{array}{l}\text { Poster Struktur Lidah Manusia } \\
(1 \times 1,5) \text { meter }\end{array}$ & 2 & Baik & Swadaya Sekolah \\
\hline 3. & $\begin{array}{l}\text { Poster Struktur tumbuhan ukuran } \\
(1 \times 1,5) \text { meter }\end{array}$ & 2 & Baik & Swadaya Sekolah \\
\hline 4. & Globe & 4 & Baik & Swadaya Sekolah \\
\hline 5. & $\begin{array}{l}\text { Poster peta dunia ukuran }(3 \times 2) \\
\text { meter }\end{array}$ & 1 & Baik & Swadaya Sekolah \\
\hline 6. & $\begin{array}{l}\text { Poster peta Indonesia ukuran } \\
(3 \times 2) \text { meter }\end{array}$ & 1 & Baik & Swadaya Sekolah \\
\hline 7. & $\begin{array}{l}\text { Poster peta Nusa Tenggara Timur } \\
\text { ukuran }(3 \times 2) \text { meter }\end{array}$ & 2 & Baik & Swadaya Sekolah \\
\hline 8. & $\begin{array}{l}\text { Model bangun datar persegi } \\
\text { ukuran }(10 \times 10) \text { cm }\end{array}$ & 10 & Baik & Swadaya Sekolah \\
\hline 9. & $\begin{array}{l}\text { Model bangun datar Persegi } \\
\text { Panjang }\end{array}$ & 10 & Baik & Swadaya Sekolah \\
\hline 10. & Model bangun datar segitiga & 10 & Baik & Swadaya Sekolah \\
\hline 11. & Model bangun ruang kubus & 2 & Baik & Swadaya Sekolah \\
\hline 12. & Model bangun ruang balok & 2 & Baik & Swadaya Sekolah \\
\hline & & & \\
\hline
\end{tabular}


Menurut data yang dipaparkan pada tabel di atas terdapat beberapa media pembelajaran geometri yang dapat digunakan untuk mengajarkan konsep bangun datar dan bangun ruang.Media-media ini dapat digunakan untuk mengenalkan bangun datar dan bangun ruang. Fokus pengenalan bangun datar dan bangun ruang ditanamkan secara dini dimulai pada kelas II dan kelas III.

Jumlah siswa kelas II di SD Bertingkat Naikoten I adalah 63 orang yang terbagi dalam 3 kelas. Rata-rata satu kelas menampung 21 orang siswa. Sedangkan jumlah siswa kelas III sebanyak 92 orang yang terbagi dalam 4 kelas. Jadi, rata-rata 1 kelas menampung sampai 23 orang siswa. Hal ini berarti, model-model bangun datar dan bangun ruang yang tersedia harus digunakan untuk mengenalkan konsep bangun datar dan bangun ruang di 7 kelas. Dengan kata lain, 10 buah model bangun persegi, 10 buah model bangun persegi panjang, 10 buah model segitiga, 2 buah model kubus, 2 buah model balok, 2 buah model prisma dan limas harus digunakan untuk mengenalkan bangun-bangun tersebut di 7 kelas atau 155 orang siswa.

Berdasarkan Tabel 1, dapat dilihat bahwa ukuran-ukuran bangun datar persegi, persegi panjang, jajargenjang, trapesium $(10 \times 10,10 \times 15,10 \times 15,12 \times 15$ centimeter $)$ terlihat sangat kecil bila harus digunakan dalam 1 ruang kelas yang memuat siswa sampai 38 orang. Sama halnya dengan ukuran-ukuran bangun ruang kubus, balok, prisma limas dan bangun ruang sisi lengkung lainnya. Dengan demikian, bila dilihat dari segi penampilan dan kualitas, media yang tersedia belum dapat digunakan secara maksimal untuk menjawab kepuasaan siswa. Sementara kondisi idealnya, media pembelajaran harus bisa dilihat dengan jelas, digunakan atau dipakai sendiri oleh siswa.

Berdasarkan data yang telah dipaparkan di atas, bahwa media pembelajaran matematika yang tersedia adalah model-model bangun datar dan bangun ruang yang terbatas penggunaanya. Media-media ini hanya dapat digunakan untuk mengenalkan jenis-jenis dan sifat-sifat bangun datar dan bangun ruang kepada siswa SD kelas II dan Kelas III. Dengan demikian, untuk pembelajaran geometri khusus materi bangun datar pun masih belum terjawab semua kebutuhan siswa.

Ketersediaan media pembelajaran matematika yang terbatas menjadi permasalahan sekolah mitra yang harus diselesaikan. Selain karena tidak ada buku sumber tentang pembuatan dan penggunaan media pembelajaran matematika, guru-guru sekolah mitra ini juga mengalami kesulitan dalam mengembangkan media pembelajaran matematika. Bahkan ada juga tidak bisa menggunakan media pembelajaran matematika. Ada juga yang berasumsi bahwa menggunakan media pembelajaran membuang-buang waktu, tidak praktis dan sulit bagi anak-anak. Padahal, bila guru-guru mampu menggunakannya dengan baik ataupun bisa merencanakan pembelajaran dengan matang maka media dapat digunakan secara benar dan efektif. Pembelajaran akan lebih menyenangkan dan bermakna bagi siswa.

Berdasarkan analisis kebutuhan di atas, maka diperlukan suatu tindakan intensif melalui pelatihan pembuatan media pembelajaran matematika bangun datar bagi guru-guru di SD Negeri Bertingkat Naikoten guna mengatasi keterbatasan jumlah dan penggunaan media pembelajaran matematika khususnya bangun datar di kelas. 


\section{METODE}

Bentuk kegiatan pengabdian masyarakat ini adalah workshop. Metode-metode yang dilakukan dalam workshop ini adalah seminar, pelatihan, presentasi, diskusi, tanya jawab, ceramah, dan demonstrasi.

Program pengabdian masyasrakat ini dilaksanakan dalam beberapa tahapan, yaitu:

\section{Persiapan}

Kegiatan persiapan yang dilakukan adalah menentuan jadwal kegiatan, menetapkan peserta kegiatan, menyusunan modul pembuatan media pembelajaran matematika bangun datar dan menyusun modul penggunaan media pembelajaran matematika bangun datar.

\section{Pelaksanaan}

Bentuk kegiatan ini adalah workshop. Metode yang digunakan antaralain seminar, pelatihan dan demosntrasi. Tiap kegiatan dilakukan sepanjang kegiatan dan pada akhir kegiatan

a) Seminar

Adapun kegiatan-kegiatan yang dilakukan dalam seminar ini adalah ceramah, diskusi dan tanya jawab.

b) Pelatihan

Adapun kegiatan-kegiatan dalam workshop ini yaitu demonstrasi pembuatan media pembelajaran matematika, pembagian kelompok kerja, pendampingan dan pelatihan penggunaan media pembelajaran matematika

\section{HASIL DAN PEMBAHASAN}

Pelatihan pembuatan media pembelajaran matematika bangun datar bagi guru-guru SD Negeri Bertingkat Naikoten di laksanakan dalam beberapa tahapan yaitu:

\section{Persiapan}

Persiapan kegiatan dilakukan dimulai dari bulan Mei - Agustus 2020. Tim PKM menetapkan jadwal kegiatan, melakukan koordinasi dengan sekolah mitra dan menyiapkan modul pembuatan dan penggunaan media pembelajaran matematika bangun datar

\section{Pelaksanaan}

Kegiatan ini dilaksanakan dalam beberapa tahapan yaitu

a. Seminar

Kegiatan seminar ini dilaksanakan pada tanggal 08 Agustus 2020 yang bertempat di SD Negeri Bertingkat Naikoten. Peserta dari seminar ini adalah guru-guru SD Negeri Bertingkat Naikoten yang berjumlah 27 orang. Tujuan dari kegiatan seminar ini adalah membekali peserta dengan pengetahuan awal tentang pembelajaran matematika yang bermakna melalui pemanfaatan media pembelajaran/alat peraga. Pengetahuan awal yang diberikan adalah pengenalan tentang jenis-jenis media pembelajaran matematika, manfaat dan penggunaan media pembelajaran matematika di sekolah dasar melalui penerapan model pembelajaran tematik. 


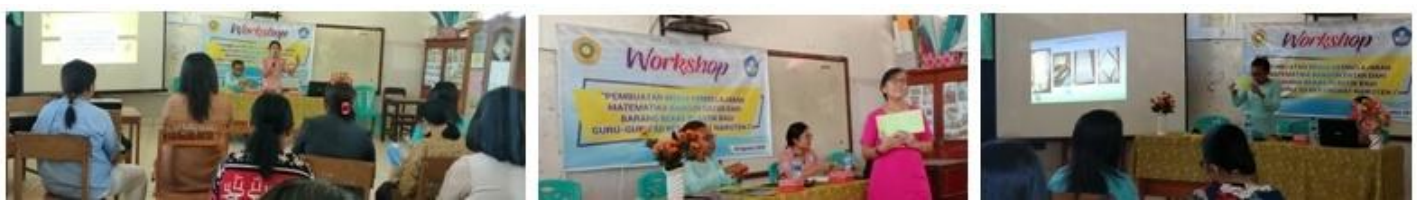

Gambar 1. Kegiatan Seminar Pembuatan Media Pembelajaran Matematika

b. Workshop pembuatan media pembelajaran matematika bangun datar

Kegiatan workshop ini berlangsung selama tiga hari. Kegiatan dilaksanakan dari tanggal 09 - 11 Agustus 2020 di SD Negeri Bertingkat Naikoten. Kegiatan ini dilakukan. Melalui pendampingan dan bantuan dari tim PKM Program Studi Pendidikan Matematika FKIP Undana, peserta membuat media pembelajaran bangun datar secara berkelompok.

Media yang akan dihasilkan dari kegiatan ini yaitu model bangun datar persegi sebanyak 5 buah, model bangun datar persegipanjang sebanyak 5 buah, model bangun datar jajargenjang sebanyak 5 buah, model bangun datar layang-layang sebanyak 5 buah, model bangun datar belah ketupat sebanyak 5 buah, model bangun datar segitiga sebanyak 5 buah, model bangun datar lingkaran sebanyak 5 buah, media Luas Persegi dan Persegi panjang 1 paket, media luas jajargenjang 1 paket, media luas luas belahketupat 1 paket, media luas layang-layang 1 paket, media luas segitiga 1 paket dan media luas lingkaran 1 paket.

Hasil dari kegiatan selama tiga hari ini menunjukkan bahwa $90 \%$ guru-guru di SD Negeri Bertingkat Naikoten mampu membuat media pembelajaran dari beberapa bahan yang disiapkan oleh Tim Pengabdian ini. Guru-guru menghasilkan 13 jenis media pembelajaran bangun datar yang memenuhi karakteristik media. Hal ini sejalan dengan pendapat Yaumi (2018), bahwa karakteristik media pembelajaran adalah relia, visibel dan visual.
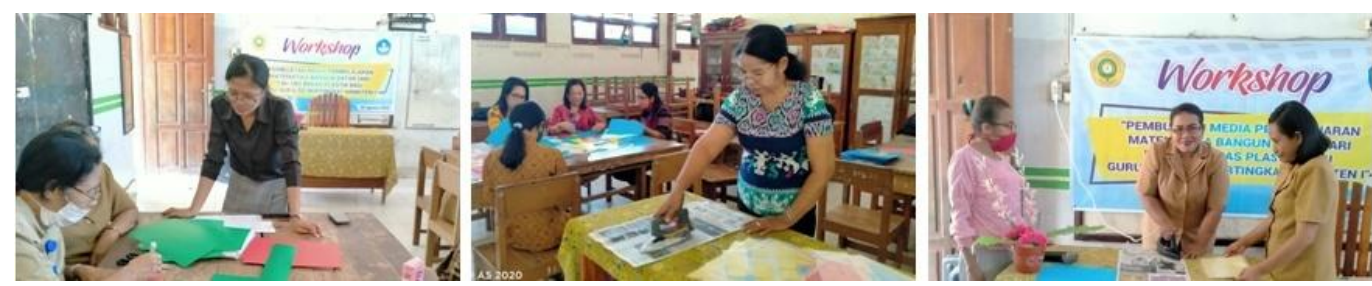

Gambar 2. Workshop Pembuatan Media Pembelajaran Bangun Datar

Tujuan utama dari kegiatan ini adalah meningkatkan keterampilan guru dalam membuat media pembelajaran matematika. Hasil kegiatan ini sejalan dengan hasil workshop pembuatan media pembelajaran yang dilakukan oleh Deda dan Disnawati (2019) bahwa workshop pembuatan media pembelajaran matematika mampu meningkatkan kemampuan dan keterampilan guru dalam merancang media pembelajaran matematika.

Tujuan jangka panjang yang diharapkan agar guru lebih kreatif lagi dalam merancang media pembelajaran yang menarik, kreatif dan inovatif untuk mengajarkan semua konsep-konsep matematika di sekolah dasar. Guru mampu mengintegrasi berbagai penggunaan teknologi. Lebih jauh lagi guru mampu memanfaatkan kearifan lokal merancang media pembelajaran bahkan juga untuk merancang perangkat-perangkat 
pembelajaran lainnya sebagaimana hasil dari pengabdian yang ditulis oleh Deda dan Amsikan (2018) bahwa guru-guru mampu memanfaatkan potensi-potensi lokal di Kefamenanu seperti Laku Tobe, Jambu Biji, Ume Kbubu dan Tenunan untuk merancang pembelajran yang bermakna bagi siswa.

Dengan demikian, melalui kegiatan pelatihan ini, guru-guru diharapkan mampu mengembangkan media pembelajaran sesuai dengan kebutuhan pembelajaran di kelas. Media yang dirancang dikondisikan dengan keadaan sosial-budaya, lingkungan dan kebiasaan siswa sehari-hari.

c. Pelatihan Penggunaan Media Pembelajaran Matematika

Dalam kegiatan ini, tim PKM Program Studi Pendidikan Matematika FKIP Undana membekali guru-guru di SD Negeri Bertingkat Naikoten menggunakan media pembelajaran bangun datar di kelas. Tim PKM mengidentifikasi kesulitan-kesulitan peserta dalam menggunakan media pembelajaran di kelas melalui kegiatan diskusi dan memberi solusi terkait kesulitan yang dihadapi. Tim PKM juga mendemonstrasikan penggunaan media pembelajaran matematika di kelas dengan model pembelajaran tematik.

Kegiatan diskusi ini menghasilkan beberapa temuan, yaitu, guru sulit dalam menerapkan pembelajaran tematik untuk pembelajaran matematika, guru lebih banyak mengajarkan matematika tanpa menerapkan model tematik sehingga matematika lebih banyak diajarkan sebagai prosedur yang perlu dihafal. Selain itu, terkait pengetahuan guru tentang materi bangun datar, guru kurang memahami konsep luas dan keliling bangun datar. Hal ini menjadi salah satu penyebab guru tidak mampu merancang pembelajaran yang bermakna bagi siswa. Padahal, dengan pembelajaran yang bermakna dapat menumbuhkan motivasi siswa dalam mempelajari matematika. Bila tidak ada motivasi dan minat siswa maka pelajaran matematika menjadi hal yang sulit bagi siswa.

Menurut Sumardjan (2017), terdapat dua faktor yang mempengaruhi prestasi belajar siswa, yaitu, faktor intern dan faktor ekstern. Lebih lanjut diungkapkan bahwa, faktor intern adalah faktor dalam diri siswa yang meliputi kecakapan, minat, bakat, usaha, motivasi, perhatian, kelemahan, dan kesehatan serta kebiasaaan siswa. Minat, motivasi dan perhatian siswa dapat dikondisikan oleh guru melalui proses pembelajaran di kelas. Hal ini berati, bila guru mampu merancang pembelajaran yang bermakna bagi siswa dengan memilih model pembelajaran yang tepat, melalui pemberian masalah kontekstual, dan dengan bantuan benda-benda konkrit dapat menumbuhkan minat, bakat dan motivasi belajar matematika bagi siswa.

\section{SIMPULAN}

Kegiatan Pelatihan Pembuatan Media Pembelajaran Matematika yang dilaksanakan oleh Tim Pengabdian Program Studi Pendidikan Matematika FKIP Universitas Nusa Cendana mampu meningkatkan kemampuan dan keterampilan guru-guru di SD Negeri Bertingkat Naikoten dalam membuat media pembelajaran matematika bagi siswa sekolah dasar. Luaran lainnya dari kegiatan ini adalah tersedianya modul petunjuk pembuatan media pembelajaran matematika bangun datar dan petunjuk penggunaan media di kelas. 


\section{UCAPAN TERIMAKASIH}

1. Ucapan terimakasih kepada Dekan Fakultas Keguruan Ilmu Pendidikan Universitas Nusa Cendana yang telah mengijinkan Tim PKM melaksanakan Program Kemitraan Masyarakat

2. Ucapan terimakasih kepada Kepala SD Negeri Bertingkat Naikoten yang telah berkenan memberikan berbagai data terkait kegiatan pengabdian yang dilaksanakan oleh Tim PKM Program Studi Pendidikan Matematika FKIP Universitas Nusa Cendana

3. Ucapan terimakasih kepada guru-guru SD Negeri Bertingkat Naikoten yang telah berpartisipasi aktif dalam kegiatan pelatihan dari awal sampai akhir kegiatan.

\section{DAFTAR PUSTAKA}

Amsikan, S. \& Deda, Y. N. 2018. Memanfaatkan Potensi Lokal Kefamenanu dalam Pembelajaran Matematika untuk Meningkatkan Kreatiifitas Guru SMP. Ethos: Jurnal Pengabdian Masyarakat, 1(1); 32-40

Deda, Y. N. \& Disnawati, H. 2019. Workshop Media Alat Peraga Matematika "Luas Bangun Datar" untuk Meningkatkan Kreatifitas Guru dan Siswa Sekolah Dasar. Ethos : Jurnal Pengabdian Masyarakat, 8(1); 67 -72

Mashuri, S. 2019. Media Pembelajaran Matematika. Yogyakarta : Deepublish

Riyana, C. 2012. Media Pembejaran. Jakarta Pusat : Direktorat Jenderal Pendidikan Islam, Kementerian Agama RI

Sumardjan. 2017. Desain Pembelajaran MTK SD Menyenangkan. Semarang : Formaci Press

Yayuk, E. 2019. Pembelajaran Matematika Sekolah Dasar. Malang: Universitas Muhammadiyah Malang.

Yaumi, M. 2018. Media dan Teknologi Pembelajaran. Jakarta : Prenamedia Grup 